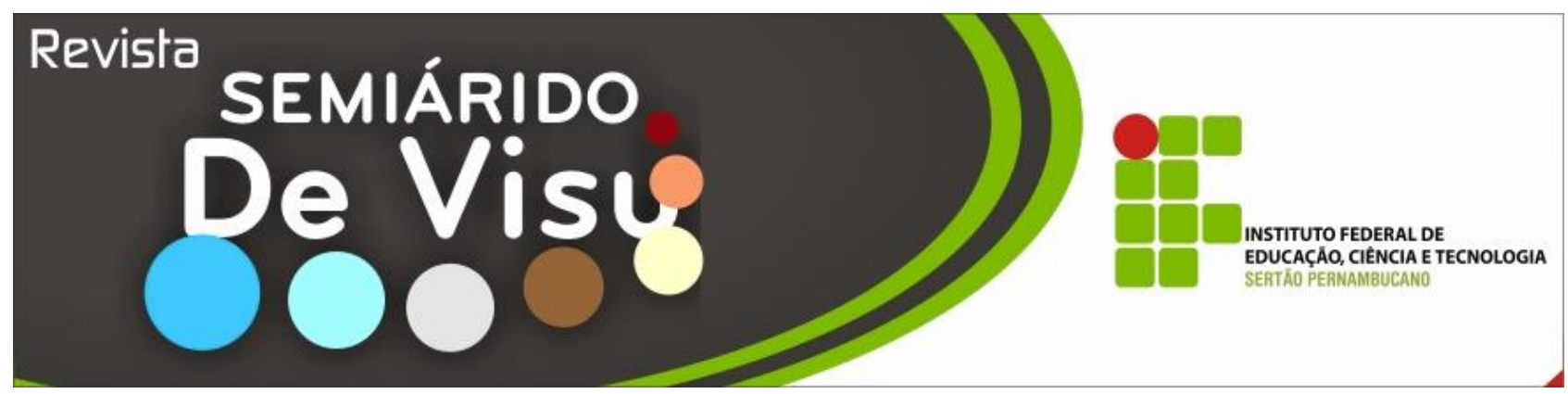

\title{
Fenologia e níveis de prolina em cacaueiros consorciados com mangueiras no Vale do Submédio São Francisco
}

\author{
Marcelo de Campos Pereira1, Laise de Sousa Santos², Elica Santos Rios ${ }^{3}$, Essione Ribeiro de \\ Sousa $^{4}$, Valtemir Gonçalves Ribeiro ${ }^{5}$ \\ ${ }^{1}$ Instituto Federal do Sertão Pernambucano - campus Salgueiro. BR 232, Km 508, sentido Recife, Zona Rural - Salgueiro - \\ Pernambuco - Brasil. CEP: 56000-000 / Telefone: (87) 3421-0050 / E-mail: marcelo.pereira @ifsertao-pe.edu.br; \\ 2,3,4,5 Universidade do Estado da Bahia - campus III. Av Edgard Chastinet, s/n - Juazeiro - Bahia - Brasil. CEP: 48905-680/ \\ Telefone: (74) 3611-5617 / E-mail: laysousa1@hotmail.com, lk.rios@ hotmail.com, essione.r@ hotmail.com, \\ valtemir.ribeiro@gmail.com;
}

\begin{abstract}
RESUMO: Em clones de cacaueiros CCN-51, PH-16 e PS-1319, com 14 meses de idade, plantados em consórcio com mangueiras das cultivares Tommy Atkins e Haden de 10 anos de idade, no Vale do Submédio São Francisco - Brasil, foram avaliados no período de agosto de 2009 a julho de 2010 o número de folhas emitidas, altura da planta, diâmetro de caule, teores de prolina nas folhas e percentual de florescimento. Houve diferença estatística significativa para a variável altura dos clones, no período de agosto de 2009 a julho de 2010. O clone CCN-51 apresentou crescimento superior a PH-16 e PS-1319, tendo médias de altura de 70,44 cm, $62,76 \mathrm{~cm}$ e $61,55 \mathrm{~cm}$, respectivamente. Os clones analisados não apresentaram diferenças significativas em relação ao diâmetro do colo. No decorrer do período experimental, os clones PS-1319, PH-16 e CCN-51 apresentaram valores médios de número de folhas por planta estatisticamente equivalentes a 22,9, 32,12 e 39,54, respectivamente. O CCN-51 e PH-16 apresentaram maiores níveis de prolina e de incidência floral em comparação ao clone PS-1319.
\end{abstract}

Palavras-chave: Theobroma cacao L., sistemas de produção, aminoácido.

\section{Phenology and levels of proline in cocoa consortium with mango tree in the São Francisco River Valley}

\begin{abstract}
In cocoa cloned CCN-51, PH-16 and PS-1319, with 14 months old, planted in consortium with mango cultivars Tommy Atkins and Haden, with 10 years old, in the San Francisco River Valley - Brazil, were evaluated from august 2009 to july 2010, the number of emitted leaves, plant height, stem diameter, proline accumulation in leaves and flowering percentage. The Clone CCN-51 grew more than PH-16 and PS-1319, with average height of $70.44 \mathrm{~cm}, 62.76$ $\mathrm{cm}$ and $61.55 \mathrm{~cm}$, respectively. The analyzed clones showed no significant differences in relation to the diameter. During the experimental period, clones PS-1319, PH-16 and CCN-51 had mean leaf number statistically equivalent to 22.9, 32.12 and 39.54, respectively. The CCN-51 and PH-16 had higher levels of proline and floral incidence in comparison to clone PS-1319.
\end{abstract}

Keywords: Theobroma cacao L., production systems, amino acid. 
(PEREIRA et al., 2016)

\section{Introdução}

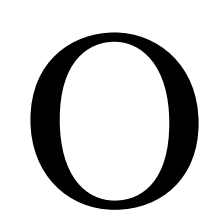

cacaueiro (Theobroma cacao L.) é uma planta perene da família Esterculiaceae, originária da região amazônica, de grande importância econômica (AMEIDA \& CHAVES, 2010). Segundo dados do IBGE (2011), o Brasil produziu 233,71 mil toneladas de amêndoas de cacau em 2010, sendo as Regiões Norte/Nordeste responsáveis por mais de 96,5\% dessa produção. Nesse mesmo ano, o Nordeste produziu 149,30 mil toneladas das amêndoas do fruto, respondendo a Bahia por $100 \%$ da produção regional e cerca de $64 \%$ da nacional.

Na região Sul da Bahia, cultiva-se o T. cacao sob sombra de árvores da Mata Atlântica em sistema de 'Cabruca' ou com outras árvores de valor econômico (ALMEIDA \& VALLE, 2007). O cacaueiro também é consorciado ao redor do mundo em sistemas planejados com outras espécies de valor econômico como palmeira de betel (Areca catechu), coqueiro (Cocos nucifera L.), seringueira (Hevea brasiliensis Muell. Arg.), craveiro (Syzigium aromaticum (L.) Merr. e L. M. Perry), caneleira (Cinnamomum zeylanicum Breyn.), corticeira (Erythrina fusca Lour.), entre outras espécies amazônicas (BRITO et al., 2002).

O seu cultivo depende das condições edafoclimáticas locais, necessitando de condições parecidas às encontradas nas regiões do trópico úmido, ou seja, altos índices de temperatura e de umidade relativa do ar para obterem uma produção satisfatória (ALVIM, 1975). Segundo Wood (1985), os solos ideais para o cultivo do cacaueiro devem apresentar excelentes características físico-químicas; o clima deve ser quente e úmido; a precipitação pluviométrica superior a $1800 \mathrm{~mm}$ anuais e temperaturas médias mensais de $24^{\circ} \mathrm{C}$, com umidades relativas do ar médias mensais superiores a $75 \%$.

O déficit hídrico pode levar as células a perder sua turgidez, dependendo da sua intensidade (BIANCHI et al., 2007), provocar alterações nos processos de expansão celular, na fotossíntese (pela diminuição da área foliar, murchamento e enrolamento de folhas $\mathrm{e}$ fechamento de estômatos) e afetar outros processos, como brotação, polinização, absorção de nutrientes e translocação de fotossintatos (BERGAMASCHI, 1992). As tensões de água no solo, segundo Orlov (1985), dependem do tipo de solo e podem variar entre $15 \mathrm{kPa}$ a $25 \mathrm{kPa}$ para solos arenosos e de 40 $\mathrm{kPa}$ a $60 \mathrm{kPa}$ para solos argilosos.

O impacto dos fatores ambientais sobre o crescimento e a produtividade do cacaueiro depende em grande parte das características genéticas que determinam as atividades fisiológicas e morfológicas da planta. A capacidade das mudas crescerem rapidamente, quando sombreadas, é um mecanismo importante de adaptação da espécie. A adaptação de plantas a baixas intensidades luminosas é ditada pelas características genéticas de cada planta em interação com o ambiente, capacitando a um uso efetivo da radiação solar disponível (SCALON et al., 2002).

A fisiologia do cacaueiro apresenta períodos com relativa definição. Do plantio ao início da produção econômica tem-se o período juvenil, cuja duração varia entre três e cinco anos (DIAS et al., 2003). A ocorrência de déficit hídrico no solo é o fator mais importante na determinação do rendimento das espécies (BIANCHI et al., 2007). Vários fatores endógenos estão associados à adaptação das plantas às condições de estresse. A concentração de prolina em plantas sob condições normais corresponde a menos de 5\% dos aminoácidos totais livres, e nas várias formas de estresse, a sua concentração pode chegar a $80 \%$ do total (ALIA, 2003). A prolina é um dos aminoácidos mais comumente associados a respostas ao estresse hídrico. Seu acúmulo ocorre no citoplasma de células de folhas, colmos e raízes, sendo a capacidade de acúmulo e sua concentração decrescentes com a idade da folha.

As plantas podem acumular prolina (NAYYAR \& WALIA, 2003; YAMADA et al., 2005) e outros aminoácidos livres (RAI, 2002; KUSAKA et al., 2005), poliálcoois (RAMANJULU \& BARTELS, 2002) e carboidratos (CHAVES et al., 2002), de forma a se aclimatarem e/ou se adaptarem a déficits 
hídricos de diferentes níveis de intensidade. Machado (2004) verificou o aumento da concentração de prolina nas folhas de Hedyosmum brasiliense sob estresse hídrico, indicando que esta espécie apresenta a capacidade para ajustamento osmótico, além das modificações morfofisiológicas já referidas, como forma de aclimatar-se à menor disponibilidade de água. Outras funções sugeridas para a prolina são a remoção de espécies reativas de oxigênio e a interação com resíduos hidrofóbicos de proteínas, protegendoas da degradação e agregação (VALLIYODAN \& NGUYEN, 2006).

O conhecimento de aspectos do florescimento, associado às condições hídricas do ambiente e da planta, pode contribuir para o desenvolvimento de técnicas de manejo, particularmente para a cultura irrigada. Um manejo mais adequado e racional da irrigação pode promover uma uniformização da floração e, como consequência, uma maturação mais homogênea dos frutos, minimizando assim, os custos de produção ao agregar maior valor à qualidade da produção. Com este trabalho objetivou-se avaliar a fenologia e quantificar os níveis de prolina em clones de cacaueiros $\mathrm{PH}$ 16, CCN-51 e PS-1319 consorciados com mangueiras das cultivares Tommy Atkins e Haden, nas condições edafoclimáticas da região do Vale do Submédio São Francisco.

\section{Material e métodos}

O experimento foi conduzido no campo experimental da Universidade do Estado da Bahia (UNEB), campus III, localizada no município de Juazeiro, BA. Essa área se situa na região submédia da bacia do Rio São Francisco, caracterizada por possuir clima semiárido e pouca pluviosidade ao longo do ano.

Clones de Cacaueiros PH-16, CCN-51 e PS-1319, com 14 meses de idade, dispostos no espaçamento $3 \mathrm{~m}$ x $6 \mathrm{~m}$, foram cultivadas em solo tipo Neossolo Flúvico, consorciado com mangueiras (Mangifera indica L.) das cultivares Tommy Atkins e Haden de 10 anos de idade. Durante o experimento foram avaliadas as seguintes características: número de folhas emitidas, comprimento da parte aérea, diâmetro de caule (medido na região do colo da planta), teores de prolina nas folhas e a intensidade de floração emitida em quatro seções da planta, sendo uma do fuste e três das ramas. As avaliações ocorreram mensalmente durante o período agosto de 2009 a julho de 2010.

Para o suprimento das necessidades hídricas das plantas, utilizou-se sistema de irrigação localizada microaspersão, que permite criar um microclima favorável ao desenvolvimento das plantas. Diariamente foram utilizados turnos de rega de duas horas, e em períodos mais críticos, chegou-se a irrigar por três horas. Para monitoramento da tensão da água no solo, foram instalados na área tensiômetros, sendo dispostos aleatoriamente a um metro do fuste das plantas. Durante o período de avaliação do nível de prolina, o potencial hídrico médio do solo estava com 26 $\mathrm{kPa}$.

As análises dos teores de prolina foram realizadas em agosto de 2010. Amostras de 100 $\mathrm{mg}$ de folhas foram homogeneizadas manualmente em gral de porcelana, com $6 \mathrm{~mL}$ de ácido sulfosalicílico a 3\%, e depois submetidas a centrifugação de 3000 rpm, durante 10 minutos. Em seguida retirou-se $2 \mathrm{ml}$ do sobrenadante, colocando-os em tubo de ensaio, ao qual foram adicionados $2 \mathrm{ml}$ de ninhidrina ácida e $2 \mathrm{ml}$ de ácido acético glacial. Posteriormente, as amostras foram mantidas por uma hora em banho-maria a $100^{\circ} \mathrm{C}$, e o resfriamento das amostras se deu por imersão em banho de gelo, procedendo-se à leitura das amostras em espectrofotômetro aferido a 520 nm. A concentração de prolina foi determinada a partir de uma curva padrão e calculada com base no peso fresco das amostras, a partir da equação da reta oriunda de curva padrão (TORELLO \& RICE, 1986).

O delineamento experimental utilizado foi $\mathrm{o}$ de blocos casualizados, com três tratamentos (PH-16, CCN-51 e PS-1319), seis repetições, com oito plantas por parcela. Os dados das variáveis fenológicas e dos teores de prolina foram submetidos à análise de variância 
(PEREIRA et al., 2016)

e as médias comparadas pelo teste Tukey, a 5\% de probabilidade, por intermédio do programa estatístico Assistat, sendo o mais indicado para tal pesquisa.

\section{Resultados e discussão}

Houve diferença estatística significativa para a variável altura dos clones, no período de agosto de 2009 a julho de 2010. O clone CCN51 apresentou crescimento superior a $\mathrm{PH}-16$ e PS-1319, tendo médias de altura de $70,44 \mathrm{~cm}$, $62,76 \mathrm{~cm}$ e $61,55 \mathrm{~cm}$, respectivamente (Gráfico $1)$.

Em relação às alturas das plantas, verificadas no presente trabalho, e contrastando com os resultados de outros autores, a exemplo de Pereira et al. (2009) que trabalhando com mudas seminais de cacau na região semiárido da Bahia, observaram crescimento superior de mudas seminais do clone PS-1319 $(35,1 \mathrm{~cm})$ em relação aos clones CCN-10, CCN-51 e PH16 que apresentaram crescimento de 23,4, 32,8 e $28,7 \mathrm{~cm}$, respectivamente.

Segundo Leite (2006) o aumento na taxa de crescimento das plantas pode ser influenciada pelo material genético em interação com as condições de solo e clima, nutrição e disponibilidade de água.

Em relação aos resultados referentes ao diâmetro do caule, os clones CCN-51, PS-1319 e PH-16 apresentaram valores similares durante todo período de avaliação, não diferindo estatisticamente entre si (Gráfico 2). Os resultados estão coerentes aos de Leite (2006), que estudando diversos clones de cacau, dentre eles o PH-16 e o CCN-51, com 21 meses de idade, no município de Nova Redenção na Bahia, verificou diâmetros de colo semelhantes $(35,8 \mathrm{~mm})$, nas plantas avaliadas. Já Almeida \& Chaves (2010), analisando mudas da variedade seminal Forasteiro e clonal CCN-51, observaram que o diâmetro caulinar das mudas clonais foi maior do o que das mudas seminais, no período inicial do desenvolvimento das mesmas, observando-se, em seguida, uma evolução superior do diâmetro caulinar das mudas seminais.

Entre agosto de 2009 a fevereiro de 2010, houve uma tendência do clone PS-1319 apresentar um menor número de folhas. De março a julho de 2010 os clones PS-1319, PH16 e CCN-51 apresentaram taxas crescentes e semelhantes entre si de enfolhamento. No decorrer do período experimental, os clones PS-1319, PH-16 e CCN-51 apresentaram valores médios de número de folhas estatisticamente equivalentes a 22,9, 32,12 e 39,54, respectivamente (Gráfico 3).

Almeida \& Chaves (2010), analisando mudas da variedade seminal Forasteiro e da clonal CCN-51, aos 11 meses, encontraram valores médios de número de folhas de 17,4 e 16,2, respectivamente. Essa diferença pode ter ocorrido em virtude das condições experimentais em que os trabalhos foram conduzidos. Uma vez que Almeida \& Chaves (2010) conduziram seus trabalhos em viveiro e as mudas foram acondicionadas em sacos pretos de polietileno mantidos sob sombrite que permitia a passagem de $50 \%$ luminosidade.

De acordo com os dados da Estação Agrometeorológica local, o mês de novembro de 2009 caracterizou-se por altas temperaturas e radiação solar de $35,2{ }^{\circ} \mathrm{C}$ e $466,1 \mathrm{ly} / \mathrm{dia}$, respectivamente, fato este que pode justificar a maior queda de folhas dos clones $\mathrm{PH}-16 \mathrm{e}$ CCN-51 no período. A longevidade das folhas do cacaueiro é influenciada pela radiação solar que receberam durante a sua ontogenia. As folhas que recebem maior radiação solar possuem menor longevidade. A área foliar está diretamente relacionada à genética de dada variedade, contudo, pode ser influenciada por fatores ambientais como a falta ou excesso de água, ataque de insetos ou doenças, densidade populacional e por práticas de manejo (MULLER \& VALLE, 2008). 
(PEREIRA et al., 2016)

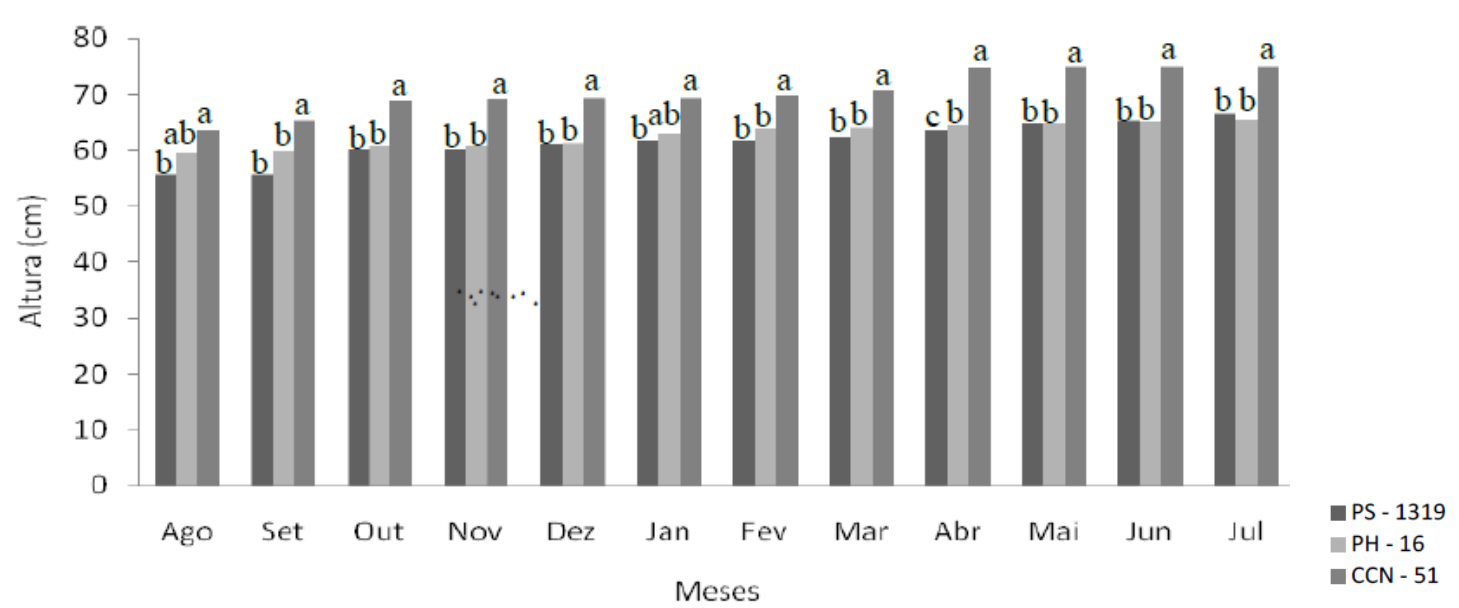

Gráfico 1. Altura dos clones PS-1319, PH-16 e CCN-51, no período de agosto de 2009 a julho de 2010 (Fonte: Pesquisa direta).

*Letras iguais não diferem entre si pelo teste Tukev, a 5\% de probabilidade.

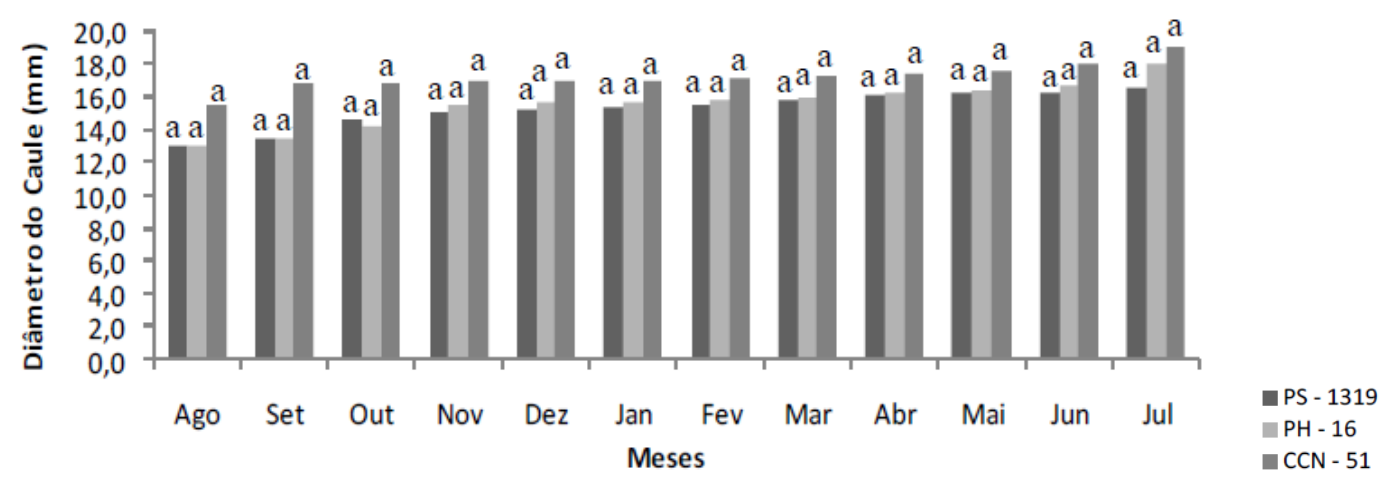

Gráfico 2. . Diâmetro do caule dos clones PS-1319, PH-16 e CCN-51, no período de agosto de 2009 a julho de 2010 (Fonte: Pesquisa direta).

*Letras iguais não diferem entre si pelo teste Tukey, a 5\% de probabilidade.

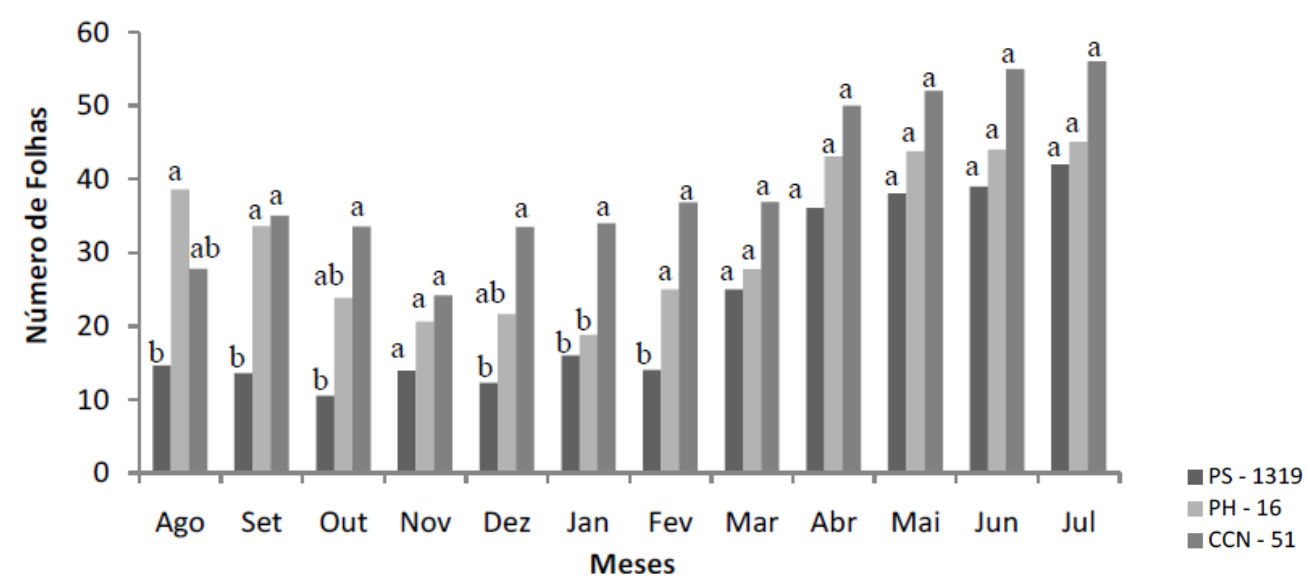

Gráfico 3. Número de folhas dos clones PS-1319, PH-16 e CCN-51, no período de agosto de 2009 a julho de 2010 (Fonte: Pesquisa direta).

*Letras iguais não diferem entre si pelo teste Tukey, a 5\% de probabilidade. 
Quanto às análises dos teores de prolina (Quadro 1), observou-se que os valores foram maiores para os clones PH-16 e CCN-51 do que para o PS-1319.

Há poucos trabalhos referentes aos mecanismos fisiológicos que compõem a resistência e deficiência hídrica no cacaueiro. Em plantas de Andiroba (Carapa guianensis Aubl.), sob deficiência hídrica, ocorreram incrementos significativos nos teores foliares de prolina, em torno de 60\% (SILVA, 2009). De modo geral, as plantas expostas aos diversos tipos de estresse ambiental tendem a concentrar prolina nos tecidos foliares, que podem atuar como moléculas sinalizadoras ou reguladoras, capazes de ativar múltiplas respostas no processo de adaptação a estresses ambientais (MAGGIO et al., 2002). De acordo com Pinho \& Ansel (1995), o acúmulo de prolina nos tecidos de folhas de plantas submetidas a estresse hídrico, pode estar associado à sua capacidade de adaptação à seca.
Durante o período de avaliação, as plantas apresentaram surtos de incidência floral (Gráfico 4), sendo que o clone PS-1319 diferiu em relação aos demais, apresentando menor índice.

A indução floral parece requerer certa maturação da planta, a qual não está necessariamente associada com a idade das árvores nem com a fase juvenil, e sim com o equilíbrio endógeno que acontece quando a planta alcança um estado em que parte dos produtos da fotossíntese são acumulados como substâncias de reserva (NUNEZ-ELISA, 1990). Todavia, houve uma estreita relação entre o maior acúmulo de prolina e a taxa de incidência floral nos clones CCN-51 e PH-16, em relação ao PS-1319, os quais tinham a mesma idade. A incidência floral pode também estar relacionada à concentração de hormônios indutores da floração que aumentam em plantas sob condições de estresse, a exemplo do etileno, envolvidos na indução floral de algumas espécies frutíferas como a mangueira (BENINCASA \& LEITE, 2002).

Quadro 1. Concentração de prolina em tecidos de folhas dos clones PS-1319, PH-16 e CCN-51.

\begin{tabular}{lll}
\hline Clones & Prolina $\left[\mathrm{mg}(\mathrm{g} . \mathrm{MS})^{-1}\right]$ & \\
\hline PH-16 & 0,13493 & $\mathrm{a}$ \\
CCN-51 & 0,09837 & \\
PS-1319 & 0,00004 & $\mathrm{a}$ \\
\hline
\end{tabular}

Fonte: Pesquisa direta. 


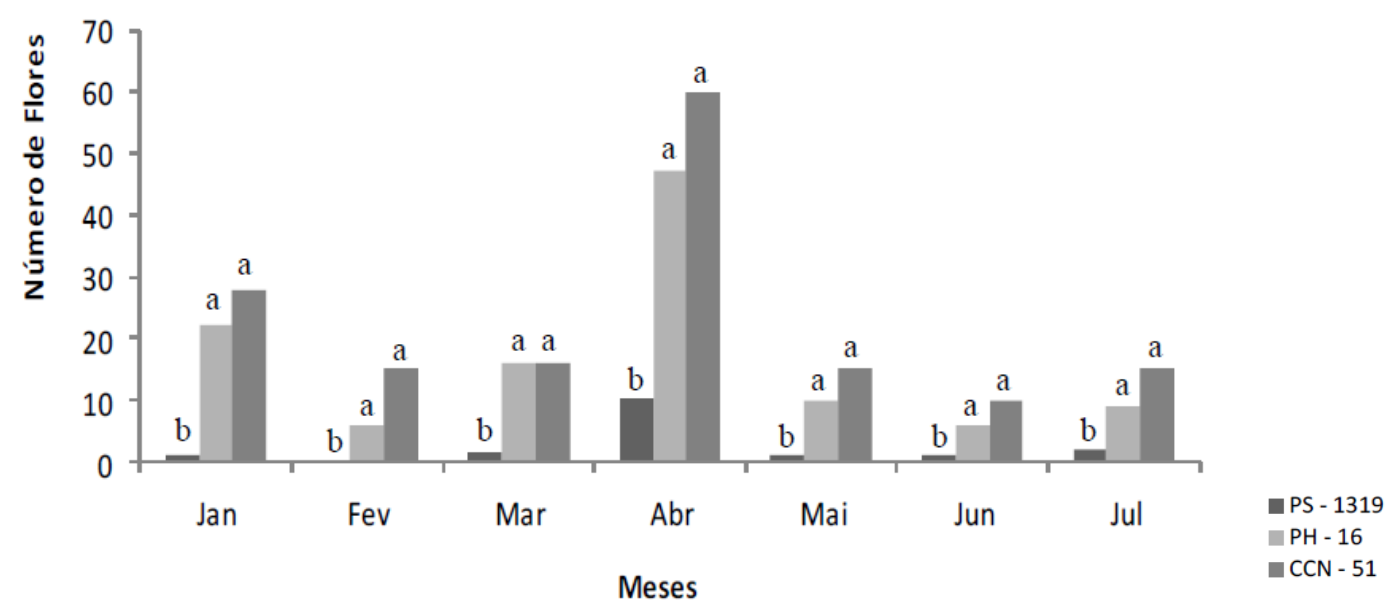

Gráfico 4. . Número de flores no período de janeiro a julho de 2010 (Fonte: Pesquisa direta).

*Letras iguais não diferem entre si pelo teste Tukey, a 5\% de probabilidade.

Com base nos resultados alcançados, há indícios que a análise de prolina pode ser utilizada na seleção de variedades clonais resistentes à vassoura-de-bruxa a serem cultivadas em ambientes sujeitos a estresse hídrico, necessitando-se, entretanto, de estudos complementares.

\section{Conclusões}

Nas condições edafoclimáticas locais, os clones CCN-51 e PH-16 apresentaram maiores níveis de prolina e de incidência floral em comparação ao PS-1319, sendo que durante o ciclo avaliado, o CCN-51 apresentou maiores taxas de crescimento em relação aos clones PH16 e PS-1319. Porém, são necessárias novas pesquisas para ratificar os resultados.

\section{Referências}

ALIA, M. Molecular mechanisms of quenching of reactive oxygen species by proline. In: 1st Annual User Meeting of the Free Radical Research Facility Daresbury, at Council for the Central Laboratory of the Research Councils, Daresbury, Cheshire, UK, 2003.
ALMEIDA, A.A.F.; VALLE, R.R. Ecophysiology of the cacao tree. Brazilian Journal of Plant Physiology, v.19, n.4, p.425448, 2007.

ALMEIDA, R.L.S.; CHAVES, L.H.G. Crescimento de mudas de cacau irrigadas por microaspersores. Revista Engenharia Ambiental, v.7, n.2, p.284-293, 2010.

ALVIM, P.T. Agricultura nos trópicos úmidos: potencialidades e limitações. Ilhéus: Ceplac/Cepec, 1975. 20p.

BENINCASA, M.M. P.; LEITE, I.C. Fisiologia Vegetal. Jaboticabal: Funep, 2002. $168 \mathrm{p}$.

BERGAMASCHI, H. Desenvolvimento de déficit hídrico em culturas. In: Bergamaschi, $\mathrm{H}$. Agrometeorologia aplicada à irrigação. $1 \mathrm{ed}$. Porto Alegre - RS: UFRGS, 1992.p. 25-32.

BIANCHI, C.A.M.; BERGONCI, J.I.; BERGAMASCHI, H.; DALMAGO, G.A.; HECKLER, B.M.M.; COMIRAN, F. Condutância da folha em milho cultivado em plantio direto e convencional em diferentes disponibilidades hídricas. Revista Ciência Rural, v.37, n.2, p.315-322, 2007. 
BRITO, A. M.; SILVA, G.C.V.; ALMEIDA, C.M.V.C.; MATOS, P.G.G. Sistemas agroflorestais com o cacaueiro: uma tentativa de busca do desenvolvimento sustentável do estado do Amazonas, Brasil. Revista Agrotrópica, v.14, n.2, p.61-72, 2002.

CHAVES, M.M.; PEREIRA, J.S.; MAROCO, J.; RODRIGUES, M.L.; RICARDO, C.P.P.; OSÓRIO, M.L.; CARVALHO, I.; FARIA, T.; PINHEIRO, C. How plants cope with water stress in the field? Photosynthesis and growth. Annals of Botany, v.89, n.7, p.907916, 2002.

DIAS, L.A.S. SOUZA, C.A.S.; AUGUSTO, S.G.; SIQUEIRA, P.R.; MULLER, M.W. Período mínimo de colheita para avaliação de cultivares de cacau em Linhares-ES. Revista Árvore, v.27, n.4, p.495-501, 2003.

IBGE, Instituto Brasileiro de Geografia e Estatística. Levantamento Sistemático da Produção Agrícola: pesquisa mensal de previsão e acompanhamento das safras agrícolas no ano civil. Rio de Janeiro, v.24, n.2, p.1-82, 2011.

KUSAKA, M.; OHTA, M.; FUJIMURA, T. Contribution of inorganic components to osmotic adjustment and leaf folding for drought tolerance in pearl millet. Physiologia Plantarum, v.125, n.4, p.474-489, 2005.

LEITE, J.B.V. Cacaueiro: Propagação por estacas caulinares e plantio no semi-árido do estado da Bahia. 2006. $84 \mathrm{f}$. Tese (Doutorado em Produção Vegetal) - Faculdade de Ciências Agrárias e Veterinárias, Universidade Estadual Paulista, Jaboticabal, 2006.

MACHADO, A.V. Efeitos do estresse hídrico em plantas jovens de Hedyosmum brasiliense Mart. (Chloranthaceae). Florianópolis, 2004, 59p. Tese de Mestrado. Centro de Ciências Biológicas, Universidade Federal de Santa Catarina, 2004.

MAGGIO, A.; MIYAZAKI S.; VERONESE P.; FUJITA T.; IBEAS, J.I.; DAMSZ, B.;
NARASIMHAN, M.L.; HASEGAWA, P.M.; JOLY, R.J.; BRESSAN, R.A. Does proline accumulation play an active role in stressinduced growth reduction? The Plant Journal, v.31, n.6, p.699-712, 2002.

MULLER, M.W.; VALLE, R.R. Ecofisiologia do Cultivo do Cacaueiro. In: Raúl René Valle. Ciência, tecnologia e Manejo do Cacaueiro. Itabuna, v.1, p.17-41, 2008.

NAYYAR, N.; WALIA, D.P. Water stress induced proline accumulation in contrasting wheat genotypes as affected by calcium and abscisic acid. Biologia Plantarum, v.46, n.2, p.275-279, 2003.

NUNEZ-ELISEA, R. Ethylene and other endogenous factors possibly involved in mango flowering. Acta Horticulturae, n.275, p.441447, 1990.

ORLOV, D. Manejo y control del riego en plantaciones de arboles frutales. Bet-Dagan : Ministério de Agricultura de Israel, 1985. p.46.

PEREIRA, M.C.; SANTOS, L.S.; RIBEIRO, V.G.; SOUZA, E.R.; ARAÚJO, E.A.; PEIXOTO, A.R. Avaliações de porta-enxertos de cacaueiros da fase de crescimento das mudas até a enxertia no campo, no Semiárido baiano. Revista Agrotrópica, v.21.2, p.5-10, 2009.

PINHO, N.L.J; ANSEL D. Evolução de teor de prolina em cultivares de milheto (Pennisetum americanum L.) e sorgo (Sorghum bicolor (L.) Moench) em resposta ao estresse hídrico. Revista Ciência Agronômica, v.26, n.1-2, p.19, 1995.

RAI, V.K. Role of amino acids in plant resposes to stresses. Biologia Plantarum, v.45, n.4, p.481-487, 2002. http://link.springer.com/article/10.1023\%2FA\% 3A1022308229759?LI=true\#> 28 Ago. 2012.

RAMANJULU, S.; BARTELS, D. Droughtand desiccation-induced modulation of gene expression in plants. Plant, Cell and Environment, v.25, n.2, p.141-151, 2002. 
SCALON, S.P.Q.; MUSSURI, M.R.; RIGONI, M.V.F. Crescimento de mudas de espécies florestais nativas sob diferentes níveis de sombreamento. Revista Árvore, v.26, n.1, p.15, 2002.

SILVA, J.R.R. Comportamento ecofisiológico de plantas jovens de andiroba (Carapa guianensis aubl.) sob dois regimes hídricos. Belém: Universidade Federal Rural da Amazônia, 2009. 41p. Dissertação Mestrado.

SOUZA JÚNIOR, J.O; CARMELLO, Q.A.C. Formas de adubação e doses de uréia para mudas clonais de cacau cultivadas em substrato. Revista Brasileira de Ciência do Solo, v.32, n.6, p.2367-2374, 2008. http://www.scielo.br/scielo.php?pid=S0100$06832008000600015 \&$ script $=$ sci_arttext $>\quad 25$ Jul. 20012.

TORELLO, W.A.; RICE, L.A. Effects of $\mathrm{NaCl}$ stress on proline and cation accumulation in salt sensitive and tolerant turfgrasses. Plant and Soil, v.93, n.2, p.241-247, 1986. http://link.springer.com/article/10.1007\%2FBF 02374226?LI=true\#> 25 Mar. 2012.

VALLIYODAN, B.; NGUYEN, H.T. Understanding regulatory networks and engineering for enhanced drought tolerance in plants. Current Opinion in Plant Biology, v.9, n.2, p.1-7, 2006.

WOOD, G.A.R. Environment. In: Wood, G.A.R; Lass, R.A. Cocoa. 4. ed. New York: Longman, p.38-79, 1985.

YAMADA, M.; MORISHITA, H.; URANOS, K.; SHIOZAKI, N.; YAMAGUCHISHINOZAKI, K.; SHINOZAKI K.; YOSHIBA, Y. Effects of free proline accumulation in petunias under drought stress. Journal of Experimental Botany, v.56, n.417, p.1975-1981, 2005. 